\title{
BMJ Open Perception and self-management of hypertension in Chinese cardiologists (CCHS): a multicenter, large-scale cross- sectional study
}

\author{
Lei Hou, ${ }^{1,2}$ Xuejuan Jin, ${ }^{1}$ Jianying Ma, ${ }^{1}$ Juying Qian, ${ }^{1}$ Yong Huo, ${ }^{3}$ Junbo Ge ${ }^{1}$
}

To cite: Hou L, Jin X, Ma J, et al. Perception and selfmanagement of hypertension in Chinese cardiologists (CCHS): a multicenter, large-scale crosssectional study. BMJ Open 2019;9:e029249. doi:10.1136/ bmjopen-2019-029249

- Prepublication history and additional material for this paper are available online. To view these files, please visit the journal online (http://dx.doi. org/10.1136/bmjopen-2019029249).

Received 18 January 2019 Revised 05 August 2019 Accepted 12 August 2019
D) Check for updates

(C) Author(s) (or their employer(s)) 2019. Re-use permitted under CC BY-NC. No commercial re-use. See rights and permissions. Published by BMJ.

${ }^{1}$ Department of Cardiology, Shanghai Institute of Cardiovascular Diseases, Zhongshan Hospital, Fudan University, Shanghai, China ${ }^{2}$ Department of Cardiology, Tongren hospital, Shanghai Jiaotong University, School of Medicine, Shanghai, China ${ }^{3}$ Department of Cardiology, Peking University First Hospital, Beijing, China

Correspondence to

Dr Junbo Ge; gejunbo@126.com

\section{ABSTRACT}

Objectives To determine the frequency of risk factors for hypertension among Chinese cardiologists using a nationwide survey.

Design Multicenter, cross-sectional observational study. Setting 2441 hospitals across China were surveyed between September 2016 and August 2017.

Participants All in-service cardiologists were surveyed $(n=28924)$.

Interventions WeChat-based electronic data capture system, a social application in China (Tencent, Nanshan, China), was used for data acquisition. Physician subscribed to the WeChat official account of the China Cardiologist Heart Study, and filled out an online questionnaire that included age, gender, level of in-service hospital, professional title, academic degree, area of expertise and cardiovascular risk factors. All information was required.

\section{Primary and secondary outcome measures The} primary outcome was the presence of cardiovascular risk factors. The secondary outcome was the impact of the risk factors on the occurrence of hypertension.

Results Among 28924 Chinese cardiologists who completed the questionnaire, $57.6 \%$ had blood pressure of $130-139 / 80-89 \mathrm{~mm} \mathrm{Hg}(5.3 \%$ were taking antihypertensive drugs) and $22.0 \%$ had blood pressure $\geq 140 / \geq 90 \mathrm{~mm} \mathrm{Hg}$ (36.5\% were taking antihypertensive drugs). The multivariable analysis showed that age, gender, academic degree, hospital level, body mass index (BMI), smoking and comorbidities were independently associated with hypertension among cardiologists (all $\mathrm{p}<0.05)$. Age, female gender, BMI, smoking, family history of cardiovascular diseases (CVDs) and comorbidities were independently associated with taking antihypertensive drugs among hypertensive cardiologists (all $p<0.05$ ). Age, hospital level, professional title, BMI, family history of CVDs and comorbidities were independently associated with reaching target blood pressure among hypertensive cardiologists taking antihypertensive drugs.

Conclusion Chinese cardiologists do not recognise and pay attention to their own blood pressure. Their rate of antihypertensive treatment was low. The identified risk factors could be used to identify cardiologists at higher risk for hypertension and for implementing preventive interventions.

\section{Strengths and limitations of this study}

- The strength of the present study lies in its large sample size (>26000 participants) from all across China.

- Because of funding and logistics, data had to be collected using a self-filled survey, which could introduce bias compared with a formal epidemiological study.

- The medical system in China and the formation required to work in cardiology are different from that of other countries, limiting the generalisability of the data.

- The geographical distribution of the cardiologists across China was not taken into account.

\section{INTRODUCTION}

Cardiologists are exposed to threats to their health, resulting in an important incidence of orthopaedic problems. ${ }^{12}$ In addition, there is a risk of radiation-related diseases. ${ }^{23}$ Besides those obvious occupational hazards, cardiologists are exposed to stress, work overload and bad lifestyle habits that may increase their cardiovascular risk, ${ }^{45}$ and this is observed in Chinese cardiologists. ${ }^{6} 7$ A study from Italy showed that the cardiovascular profile of Italian cardiologists was far from ideal and that the perception of their own risk factors was low. ${ }^{8}$ The understanding and awareness of cardiologists' perception of their own health are not only important for maintaining individual health and the manpower of the national medical healthcare system, but also directly affect their understanding and behaviours toward the patients, eventually having some impact on the prevention and treatment of cardiovascular diseases (CVDs). Indeed, for many patients, cardiologists are role models for behavioural changes. ${ }^{9-11}$ Cardiologists' knowledge about CVD risk factors and their perception of how they treat 
their patients with CVD risk factors have an impact on their perception of their own risk factors. ${ }^{12}$

Chinese physicians face a large number of patients and are at risk of job turnover. ${ }^{13}$ A survey of Chinese cardiologists found that there were only 1.9 cardiologists per 100000 people, ${ }^{6}$ compared with 8.1 per 100000 people in the USA in 2009. ${ }^{7}$ Hence, cardiologists in China have heavy responsibilities and high work burden. Faced with such a disparity in the proportion of cardiologists and patients, the working time of Chinese doctors usually exceeds the standard working time. ${ }^{14}$ All those factors may lead to an increase in the incidence of cardiovascular risk factors and diseases among Chinese cardiologists. Indeed, comparing the Physicians' Health Study from the USA with the Chinese Cardiovascular Risk Evaluation (CARE) study, ${ }^{15}{ }^{16}$ it was found that the prevalence of cardiovascular risk factors among Chinese cardiologists was higher than among American physicians, and that Chinese cardiologists had a poor perception of their own cardiovascular risk factors. Hypertension is a major risk factor for CVDs and death in China, ${ }^{17}$ as well as in the world in general. ${ }^{18}{ }^{19}$ Hypertension may arise due to adverse lifestyle habits (tobacco, alcohol, caffeine and salty foods), ${ }^{20}$ but also due to chronic stress, work pressure and lack of sleep. ${ }^{21-25}$

A recent anecdotic observation is that sudden death was observed in many young Chinese cardiologists, prompting the hypothesis that Chinese cardiologists may neglect their own health. In addition, as stated above, Chinese cardiologists are likely to display risk factors of hypertension, which will have a certain impact on their health. Nevertheless, the factors for poor cardiovascular factors among cardiologists must first be identified and understood before interventions can be implemented. Therefore, the present study aimed to examine the risk factors for hypertension among Chinese cardiologists using a nation-wide survey.

\section{SUBJECTS AND METHODS Participants}

This was a national, multicenter, cross-sectional observational study. Cardiologists from 2441 hospitals across China were surveyed between September 2016 and August 2017. All in-service cardiologists were eligible. If a hospital did not have a department of cardiology and only had a department of internal medicine, then the internists working in the cardiovascular field were included. Physicians who were unwilling to participate in this survey were excluded.

\section{Sampling method}

Due to the study funding and lack of manpower, it was difficult to design a sampling frame according to the economic and hospital levels and randomly select hospitals nation-wide. Hence, the study used a two-stage sampling process. In the first stage, hospitals were selected using non-random stratification according to regional economic and hospital levels. In the second stage, a random proportional sample from authoritative lists was created, and all the cardiologists in this sample of hospitals were invited to participate in the study.

\section{Questionnaire}

The study was carried out and coordinated under the guidance of a scientific advisory board. Data quality was monitored by the study coordinators throughout the study.

WeChat-based electronic data capture system, a social application in China (Tencent, Nanshan, China), was used for data acquisition. Physician subscribed to the WeChat official account of the China Cardiologist Heart Study (Wuxi Boyankang Technology Development Co. was responsible for platform construction and data management), and filled out an online questionnaire that included age, gender, level of hospital, professional title (general physicians were those with a bachelor degree; healers were those with a junior college degree or below), academic degree, area of expertise, height, body weight, blood pressure, heart rate, fasting blood glucose, total cholesterol (TC), low density lipoprotein-cholesterol (LDL-C), high density lipoprotein-cholesterol (HDL-C), triglyceride (TG), current diseases, medication status, smoking history and family history. The questions about area of expertise and current diseases had multiple choices. All information was required. Questionnaires with incomplete information could not be submitted. There were logically possible upper and lower limits for the content to be filled in. If the limit was exceeded, it could indicate that the data were incorrect. The staff of the project team would remind the physician to check. The questionnaire is shown in online supplementary appendix 1.

\section{Data collection}

Demographic variables and risk factors for CVD were assessed according to standardised study protocols. Age was automatically generated based on the birth date. Blood pressure and heart rate were the average levels over the past 2 weeks. Fasting blood glucose and blood lipids were reviewed by the physician for the most recent results within a year. Body mass index (BMI) was calculated based on weight and height as $\mathrm{kg} / \mathrm{m}^{2}$. Hypertension was defined as systolic blood pressure $\geq 140 \mathrm{~mm} \mathrm{Hg}$ or diastolic blood pressure $\geq 90 \mathrm{~mm} \mathrm{Hg}$ or taking antihypertensive drugs. Reaching the target blood pressure was defined as systolic blood pressure $<140 \mathrm{~mm} \mathrm{Hg}$ and diastolic blood pressure $<90 \mathrm{~mm} \mathrm{Hg}$. Smoking history was defined as at least one cigarette/day in the past 3 months (yes, no, never smoking). Family history was defined as first-degree male relative with a CVD at $<55$ years of age or a first-degree female relative with a CVD at $<65$ years of age.

\section{Statistical analysis}

All data were analysed using SPSS V.22.0 (IBM). Continuous variables that followed the normal distribution were 
expressed as means $\pm \mathrm{SD}$, and skewed continuous variables were summarised as medians (IQR). Categorical variables were expressed as frequencies (percentage) and $\chi^{2}$ tests were used for comparison between groups. Univariable and multivariable logistic regression analyses were used to analyse the factors influencing the prevalence of hypertension, rate of medicine taking and rate of reaching the target blood pressure. For the multivariable analysis, comorbidity was defined as the presence of any other disease, or taking antidiabetic or lipid-lowering drugs. Two-sided $\mathrm{p}<0.05$ was considered as statistically significant.

\section{Patient and public involvement statement}

Patients were not involved in the study design and implementation.

\section{RESULTS}

\section{Characteristics of the participants}

A total of 30000 cardiologists across China were invited to participate in this survey, and 28924 completed the questionnaire, for a response rate of $96.4 \%$. Tables 1 and 2 and online supplementary table S1 present their characteristics. Most (42.7\%) were 30-39 years old, male $(54.5 \%)$, with a bachelor degree $(43.9 \%)$, working at a tertiary hospital $(60.1 \%)$, and were attending physicians $(46.5 \%)$. Their main areas of expertise were: hypertension $(63.9 \%)$, atherosclerosis and coronary artery diseases $(51.1 \%)$, blood lipids and metabolism $(35.1 \%)$ and heart failure $(31.4 \%)$. Most had a BMI of $18.5-23.9 \mathrm{~kg} / \mathrm{m}^{2}$ (66.7\%), fasting blood glucose $<6.1 \mathrm{mmol} / \mathrm{L}(90.0 \%)$, LDL-C $<2.60 \mathrm{mmol} / \mathrm{L} \quad(44.6 \%)$, HDL-C $\geq 1.0 \mathrm{mmol} / \mathrm{L}$ (93.5\%), TC $<5.2 \mathrm{mmol} / \mathrm{L}(86.3 \%)$ and TG $<1.7 \mathrm{mmol} / \mathrm{L}$ (53.8\%). Among them, $57.6 \%$ had blood pressure of 130-139/80-89 mm Hg (5.3\% were taking antihypertensive drugs) and $22.0 \%$ had blood pressure $\geq 140 / \geq 90 \mathrm{~mm}$ $\mathrm{Hg}$ (36.5\% were taking antihypertensive drugs). Among all cardiologists, $37.0 \%$ never smoked, $78.2 \%$ had a family history of CVDs, $25.3 \%$ had hypertension and $8.0 \%$ were taking antihypertensive drugs.

\section{Gender differences in the prevalence of hypertension in Chinese cardiologists}

Hypertension was more prevalent in male cardiologists than in females $(\mathrm{p}<0.001)$ (table 3$)$. More male cardiologists were taking antihypertensive drugs (33.5\% vs $28.8 \%$, $\mathrm{p}<0.001)$, but more female cardiologists achieved the target blood pressure $(44.3 \%$ vs $39.8 \%, \mathrm{p}=0.036)$.

\section{Age differences in the prevalence of hypertension in Chinese cardiologists}

Table 4 shows that hypertension was more prevalent in the older age groups $(\mathrm{p}<0.001)$. The highest proportions of cardiologists taking antihypertensive drugs were found in the 50-59 (42.0\%) and 60-69 (48.8\%) years age groups. The highest proportions of cardiologists reaching the target blood pressure were found in the
Table 1 Demographic characteristics, current disease and medication of the participants

\begin{tabular}{|c|c|}
\hline Variable & Total $(n=28924)$ \\
\hline Age (years) & $37.82 \pm 9.27$ \\
\hline $20-29$ & $5308(18.35)$ \\
\hline 30-39 & $12338(42.66)$ \\
\hline $40-49$ & 8019 (27.72) \\
\hline $50-59$ & $2674(9.24)$ \\
\hline $60-69$ & $584(2.02)$ \\
\hline$\geq 70$ & $1(0.00)$ \\
\hline \multicolumn{2}{|l|}{ Gender } \\
\hline Male & $15749(54.45)$ \\
\hline Female & $13175(45.55)$ \\
\hline \multicolumn{2}{|l|}{ Academic degree } \\
\hline Junior college & $225(0.78)$ \\
\hline Bachelor & $12704(43.92)$ \\
\hline Master & $10580(36.58)$ \\
\hline Doctor & $2905(10.04)$ \\
\hline Post-doctor & $412(1.42)$ \\
\hline Others & $2098(7.25)$ \\
\hline \multicolumn{2}{|l|}{ Hospital level } \\
\hline Primary & $381(1.32)$ \\
\hline Secondary & $10823(37.42)$ \\
\hline Tertiary & $17375(60.07)$ \\
\hline Others & $345(1.19)$ \\
\hline \multicolumn{2}{|l|}{ Professional title } \\
\hline General physician & $4230(14.62)$ \\
\hline Healer & $540(1.87)$ \\
\hline Resident physician & $966(3.34)$ \\
\hline Attending physician & $13448(46.49)$ \\
\hline Associate chief physician & $4674(16.16)$ \\
\hline Chief physician & $2279(7.88)$ \\
\hline Others & 2787 (9.64) \\
\hline $\mathrm{BMI}\left(\mathrm{kg} / \mathrm{m}^{2}\right)$ & $22.35 \pm 2.51$ \\
\hline$<18.5$ & $1475(5.10)$ \\
\hline $18.5-23.9$ & $19304(66.74)$ \\
\hline$\geq 24$ & $8145(28.16)$ \\
\hline \multicolumn{2}{|l|}{ Current disease } \\
\hline Coronary heart disease & $1760(6.08)$ \\
\hline Heart failure & 554 (1.92) \\
\hline Diabetes & $598(2.07)$ \\
\hline $\begin{array}{l}\text { Stroke/transient ischaemic } \\
\text { attack }\end{array}$ & $167(0.58)$ \\
\hline Chronic kidney disease & $409(1.41)$ \\
\hline Peripheral vascular disease & $431(1.49)$ \\
\hline Hypertension & $7319(25.30)$ \\
\hline
\end{tabular}

Continued 


\begin{tabular}{lc} 
Table 1 Continued & \\
\hline Variable & Total $(\mathbf{n}=\mathbf{2 8 9 2 4 )}$ \\
\hline Antihypertensive drugs & $2323(8.03)$ \\
Antidiabetic drugs & $574(1.98)$ \\
Lipid-lowering drugs & $1223(4.23)$ \\
\hline
\end{tabular}

Data are expressed as mean \pm SD or $n(\%)$.

BMI, body mass index.

20-29 (48.4\%), 30-39 (43.6\%) and 40-49 (41.7\%) years age groups. Online supplementary tables S2 and S3 show that similar patterns were observed when the analyses were performed by gender.

\section{Hospital level differences in the prevalence of hypertension in Chinese cardiologists}

Table 5 shows that the prevalence of hypertension was higher in cardiologists working at primary hospitals $(35.7 \%)$ compared with secondary $(24.9 \%)$ and tertiary $(25.4 \%)$ hospitals $(\mathrm{p}<0.001)$. The proportions of cardiologists taking antihypertensive drugs and reaching the target blood pressure were higher in secondary and tertiary hospitals (both $\mathrm{p}<0.05$ ). Similar patterns could be observed when analysing male and female cardiologists (online supplementary tables S4 and S5).

\section{Professional title differences in the prevalence of hypertension in Chinese cardiologists}

Hypertension was more prevalent in associate chief physicians and chief physicians $(\mathrm{p}<0.001)$, with a correspondingly higher proportion of cardiologists taking antihypertensive drugs $(\mathrm{p}<0.001)$. Residents, healers and attending physicians had the highest proportions of cardiologists achieving the target blood pressure $(\mathrm{p}<0.001) \quad$ (online supplementary table S6). Globally, similar patterns were observed when analysing the data by male and female cardiologists (online supplementary tables $\mathrm{S} 7$ and $\mathrm{S} 8$ ).

\section{Factors associated with hypertension among cardiologists}

Online supplementary table 9 presents the univariable and multivariable analyses of the factors associated with hypertension among Chinese cardiologists. Age (50-59 years: $\mathrm{OR}=1.397,95 \%$ CI: 1.164 to $1.678, \mathrm{p}<0.001$; $>60$ years: $\mathrm{OR}=1.949,95 \% \mathrm{CI}: 1.534$ to $2.476, \mathrm{p}<0.001$ vs $20-29$ years), female gender ( $\mathrm{OR}=0.866,95 \%$ CI: 0.813 to 0.924 , $\mathrm{p}<0.001$ vs male), academic degree (bachelor: $\mathrm{OR}=0.629$, 95\% CI: 0.461 to $0.859, \mathrm{p}=0.004$; master: $\mathrm{OR}=0.722$, $95 \%$ CI: 0.528 to $0.988, p=0.04$ vs junior college), hospital level (secondary: OR $=0.582,95 \%$ CI: 0.464 to 0.728 , $\mathrm{p}<0.001$; tertiary: $\mathrm{OR}=0.579,95 \%$ CI: 0.463 to 0.724 , $\mathrm{p}<0.001$ vs primary), BMI $\left(\geq 24 \mathrm{~kg} / \mathrm{m}^{2}:\right.$ OR $=1.314,95 \%$ CI: 1.233 to $1.400, \mathrm{p}<0.001$ vs $18.5-23.9 \mathrm{~kg} / \mathrm{m}^{2}$ ), smoking (infrequent: $\mathrm{OR}=0.568,95 \%$ CI: 0.525 to $0.613, \mathrm{p}<0.001$; never: $\mathrm{OR}=0.469,95 \% \mathrm{CI}: 0.431$ to $0.509, \mathrm{p}<0.001 \mathrm{vs}$ frequent) and comorbidities (OR=3.158, 95\% CI: 2.924
Table 2 Clinical characteristics of the participants

\begin{tabular}{lc}
\hline Variable & Total $(\mathbf{n}=\mathbf{2 8 9 2 4})$ \\
\hline SBP/DBP $(\mathrm{mm} \mathrm{Hg})$ & \\
\hline SBP & $122.74 \pm 14.27$ \\
DBP & $81.2 \pm 12.04$ \\
$<130 /<80$ & $8802(30.43)$ \\
$\begin{array}{l}\text { Taking antihypertensive } \\
\text { drugs }\end{array}$ & $228(2.59)$ \\
\hline
\end{tabular}
130-139/80-89

$13763(47.58)$

$\begin{array}{ll}\begin{array}{l}\text { Taking antihypertensive } \\ \text { drugs }\end{array} & 732(5.32) \\ \geq 140 / \geq 90 & 6359(21.99) \\ \begin{array}{l}\text { Taking antihypertensive } \\ \text { drugs }\end{array} & 2323(36.53)\end{array}$

$\begin{array}{cc}\text { Heart rate }(\mathrm{bpm}) & 74.11 \pm 9.26 \\ <50 & 1(0.00) \\ 50-59 & 778(2.69) \\ 60-69 & 6972(24.1) \\ 70-79 & 13033(45.06) \\ 80-89 & 6600(22.82) \\ \geq 90 & 1540(5.32)\end{array}$

\begin{tabular}{|cc}
\hline Fasting blood glucose $(\mathrm{mmol} / \mathrm{L})$ & $5.1 \pm 1.65$ \\
\hline$<6.1$ & $26030(89.99)$ \\
$6.1-6.9$ & $1810(6.26)$ \\
$\geq 7.0$ & $1084(3.75)$ \\
\hline LDL-C (mmol/L) & $2.73 \pm 0.87$ \\
$<2.6$ & $12888(44.56)$ \\
$2.6-3.3$ & $12058(41.69)$ \\
$3.4-4.0$ & $2363(8.17)$ \\
$\geq 4.1$ & $1614(5.58)$ \\
\hline
\end{tabular}

Unknown $1(0.00)$

\begin{tabular}{cc}
\hline $\mathrm{HDL}-\mathrm{C}(\mathrm{mmol} / \mathrm{L})$ & $1.85 \pm 1.02$ \\
$<1.0$ & $1879(6.50)$ \\
$\geq 1.0$ & $27043(93.50)$ \\
Unknown & $2(0.01)$ \\
$\mathrm{TC}(\mathrm{mmol} / \mathrm{L})$ & $4.09 \pm 1.23$ \\
$<5.2$ & $24972(86.34)$ \\
$5.2-6.1$ & $2988(10.33)$ \\
$\geq 6.2$ & $957(3.31)$ \\
Unknown & $7(0.02)$ \\
\hline $\mathrm{TG}$ (mmol/L) & $1.6(1.2,2.2)$ \\
$<1.7$ & $15547(53.75)$ \\
\hline $1.7-2.2$ & $6345(21.94)$ \\
$\geq 2.3$ & $7029(24.30)$ \\
\hline Unknown & $3(0.01)$ \\
Smoking & \\
\hline Frequent & $4660(16.11)$ \\
\hline Infrequent & $13561(46.88)$ \\
\hline
\end{tabular}

Continued 


\begin{tabular}{cc}
\hline Table 2 Continued & \\
\hline Variable & Total $(\mathbf{n = 2 8 9 2 4 )}$ \\
\hline Never & $10703(37.00)$ \\
Family history & $22611(78.17)$ \\
Yes & $6313(21.83)$ \\
\hline No & \\
\hline
\end{tabular}

Data are expressed as mean \pm SD or $\mathrm{n}(\%)$.

DBP, diastolic blood pressure; HDL-C, high density lipoproteincholesterol; LDL-C, low density lipoprotein-cholesterol; SBP, systolic blood pressure; TC, total cholesterol; TG, triglyceride.

to $3.410, \mathrm{p}<0.001)$ were independently associated with hypertension among cardiologists.

\section{Factors associated with taking antihypertensive drugs among hypertensive cardiologists}

Online supplementary table 10 presents the univariable and multivariable analyses of the factors associated with taking antihypertensive drugs among hypertensive cardiologists. Age (30-39 years: OR=1.433, 95\% CI: 1.055 to 1.945, $\mathrm{p}=0.02$; $40-49$ years: $\mathrm{OR}=1.989,95 \% \mathrm{CI}: 1.428$ to $2.771, \mathrm{p}<0.001 ; 50-59$ years: $\mathrm{OR}=2.282,95 \%$ CI: 1.599 to $3.257, \mathrm{p}<0.001 ;>60$ years: $\mathrm{OR}=2.677,95 \% \mathrm{CI}: 1.754$ to $4.086, \mathrm{p}<0.001$ vs $20-29$ years $)$, female gender $(\mathrm{OR}=1.200$, $95 \%$ CI: 1.059 to $1.359, \mathrm{p}=0.004$ vs male), BMI $(\geq 24 \mathrm{~kg} /$ $\mathrm{m}^{2}: \mathrm{OR}=1.157,95 \%$ CI: 1.031 to $1.299, \mathrm{p}=0.01$ vs $18.5-$ $23.9 \mathrm{~kg} / \mathrm{m}^{2}$ ), smoking (infrequent: $\mathrm{OR}=0.502,95 \% \mathrm{CI}$ : 0.440 to $0.572, \mathrm{p}<0.001$; never: $\mathrm{OR}=0.374,95 \%$ CI: 0.322 to $0.434, \mathrm{p}<0.001 \mathrm{vs}$ frequent), family history of CVDs $(\mathrm{OR}=1.400,95 \%$ CI: 1.247 to $1.571, \mathrm{p}<0.001)$ and comorbidities (OR=2.646, 95\% CI: 2.351 to $2.977, \mathrm{p}<0.001)$ were independently associated with taking antihypertensive drugs among hypertensive cardiologists.

\section{Factors associated with reaching target blood pressure among hypertensive cardiologists taking antihypertensive} drugs

Online supplementary table 11 presents the univariable and multivariable analyses of the factors associated with reaching target blood pressure among hypertensive cardiologists taking antihypertensive drugs. Age (50-59 years: $\mathrm{OR}=0.465,95 \%$ CI: 0.262 to $0.825, \mathrm{p}=0.009$ vs $20-29$ years), hospital level (secondary: OR=2.878, 95\% CI: 1.287 to $6.438, \mathrm{p}=0.01$; tertiary: $\mathrm{OR}=2.558,95 \%$ CI: 1.147 to $5.704, \mathrm{p}=0.02$ vs primary), professional title (residents:
$\mathrm{OR}=2.768,95 \% \mathrm{CI}: 1.467$ to $5.225, \mathrm{p}=0.002 \mathrm{vs}$ general physicians), BMI $\left(\geq 24 \mathrm{~kg} / \mathrm{m}^{2}:\right.$ OR $=0.657,95 \%$ CI: 0.548 to $0.787, \mathrm{p}<0.001$ vs $18.5-23.9 \mathrm{~kg} / \mathrm{m}^{2}$ ), family history of CVDs (OR $=0.746,95 \%$ CI: 0.624 to $0.891, p=0.001$ ) and comorbidities (OR=0.811, 95\% CI: 0.679 to $0.970, \mathrm{p}=0.02$ ) were independently associated with reaching target blood pressure among hypertensive cardiologists taking antihypertensive drugs.

\section{DISCUSSION}

Chinese cardiologists have a poor knowledge of their own cardiovascular risk factors. The present study aimed to examine the risk factors for hypertension among Chinese cardiologists using a nation-wide survey. The results suggest that Chinese cardiologists do not recognise and pay attention to their own blood pressure. Their rate of taking antihypertensive drugs was low. The identified risk factors could be used to identify cardiologists at higher risk for hypertension and for implementing preventive interventions.

In China, the prevalence of hypertension is around $24 \%,{ }^{26-28}$ leading to a significant cardiovascular burden. ${ }^{29}$ In the present study, the prevalence of hypertension was $25.3 \%$, similar to the prevalence in the general Chinese population. A previous survey of cardiologists conducted in 2011 revealed participants' characteristics that were similar to those of the present study, ${ }^{6}$ further supporting the representativeness of our sample. Of course, there is a certain overlap between the samples of the two studies, but the exact extent of this overlap cannot be confirmed.

In the present study, $57.6 \%$ of the cardiologists had borderline or at-risk blood pressure (130-139/80-89 mm $\mathrm{Hg}$ ) and only $5.3 \%$ were taking antihypertensive drugs. In addition, $22.0 \%$ had blood pressure $\geq 140 / \geq 90 \mathrm{~mm}$ $\mathrm{Hg}$, but only $36.5 \%$ were taking antihypertensive drugs. Despite the expected health knowledge in physicians compared with the general population, this rate of treatment was surprisingly not better than in the general Chinese population. ${ }^{30} 31$ The SOCRATES (the Survey on Cardiac Risk Profile and Lifestyle Habits in a Cohort of Italian Cardiologists) study showed that the rate of using lipid-lowering, antihypertensive and cardiovascular drugs was low among Italian cardiologists, ${ }^{8}$ supporting the present study. Data from the Chinese (CHARLS: China Health and Retirement Longitudinal Study) and the American (NHANES: US National Health and Nutrition

Table 3 Prevalence of hypertension, rate of antihypertensive drugs taking and rate of reaching the target blood pressure in cardiologists with different gender

\begin{tabular}{|c|c|c|c|c|}
\hline Variable & $\begin{array}{l}\text { Total } \\
(n=28924)\end{array}$ & $\begin{array}{l}\text { Male } \\
(n=15749)\end{array}$ & $\begin{array}{l}\text { Female } \\
(n=13175)\end{array}$ & $\begin{array}{l}P \\
\text { value }\end{array}$ \\
\hline Hypertension & $7319(25.30)$ & $4574(29.00)$ & $2745(20.83)$ & $<0.001$ \\
\hline Reaching the target blood pressure & 960 (41.33) & $610(39.79)$ & $350(44.30)$ & 0.036 \\
\hline
\end{tabular}

Data are expressed as $\mathrm{n}(\%)$. 
Table 4 Prevalence of hypertension, rate of antihypertensive drugs taking and rate of reaching the target blood pressure in cardiologists with different age

\begin{tabular}{|c|c|c|c|c|c|c|c|c|}
\hline Variable & $\begin{array}{l}\text { Total } \\
(n=28924)\end{array}$ & $\begin{array}{l}20-29 \\
(n=5308)\end{array}$ & $\begin{array}{l}30-39 \\
(n=12338)\end{array}$ & $\begin{array}{l}40-49 \\
(n=8019)\end{array}$ & $\begin{array}{l}50-59 \\
(n=2674)\end{array}$ & $\begin{array}{l}60-69 \\
(n=584)\end{array}$ & $\begin{array}{l}\geq 70 \\
(n=1)\end{array}$ & $P$ value \\
\hline Hypertension & 7319 (25.3) & 1276 (24.04) & $2680(21.72)$ & $2158(26.91)$ & 946 (35.38) & 258 (44.18) & $1(100)$ & $<0.001$ \\
\hline $\begin{array}{l}\text { Reaching the } \\
\text { target blood } \\
\text { pressure }\end{array}$ & 960 (41.33) & $124(48.44)$ & 322 (43.63) & 336 (41.69) & 130 (32.75) & 48 (38.10) & - & 0.001 \\
\hline
\end{tabular}

Data are expressed as $n(\%)$.

Examination Survey) general populations indicate that China had lower rates of hypertension treatment than the USA. ${ }^{27}$ This is also supported by the CARE study, which showed that physicians had suboptimal awareness of their own cardiovascular risk, as well as suboptimal use of prophylaxis, ${ }^{15} 16$ and by the SOCRATES study, which showed that the self-awareness of cardiologists' own cardiovascular risk factors was low. ${ }^{8}$ On the other hand, Abuissa et $a \hat{l}^{2}$ showed that American cardiologists had generally good lifestyle habits.

Age, gender, BMI, smoking, family history of CVDs and comorbidities are well-known risk factors for hypertension, compliance to treatment and/or achieving target blood pressure. ${ }^{33-35}$ Aboyans et $a l^{11}$ showed that the awareness and management of smoking cessation strategies among smoking French cardiologists were low. In the present study, age, gender, BMI, smoking and family history of CVDs were associated with the risk of having hypertension, with the risk of not taking the proper antihypertensive medication and with the risk of not achieving the target blood pressure. Even if age, gender and comorbidities are non-modifiable risk factors, they could help identify cardiologists in need of more efforts for seeking the proper cardiovascular treatments. This is supported by previous studies in various populations. ${ }^{30} 3637$

Great efforts are necessary to become a cardiologist in Western countries, but because of differences in the Chinese medical system, it takes less efforts to become a cardiologist in China than in Western countries, a situation that is currently being corrected. ${ }^{68-40}$ The present study suggests that having a bachelor or master degree led to lower risk of hypertension compared with junior college level. This could be due to the fact that people with more advanced training possess more skills and knowledge, leading to less stress in their work. In addition, they have higher income, decreasing the need for working long and stressful hours. This is supported by a study that showed that physicians with a low education level had poor quality of life in China. ${ }^{14}$ As more experienced physicians can have access to more advanced hospitals, we observed that cardiologists working in secondary and tertiary hospitals had a lower risk of having hypertension. This could be due to a better awareness of health knowledge in general, but also due to the better material and human resources in more advanced hospitals, thereby lowering stress and workload. ${ }^{141}$ Workload was not directly collected in the present study, but previous studies reported that it is higher in China than in the USA, with 1.9 vs 8.1 cardiologists per 100000 people. $^{67}$ Considering the large sample size in the present study, it is probable that our study population follows the national trend. One study showed that the working hours of American physicians were decreasing over the years. ${ }^{42}$ It has been shown that working long hours was associated with an increased cardiovascular risk. ${ }^{43}$ Better knowledge and lower stress/workload can also be associated with being properly treated or not for hypertension and taking the proper steps, both on the medical and lifestyle points of view, to achieve the blood pressure targets, as observed in the present study. This is supported by a number of studies in the Chinese general population. ${ }^{30} 314445$

The strength of the present study lies in its large sample size (>26000 participants) from all across China. On the other hand, because of funding and logistics, data had to

Table 5 Prevalence of hypertension, rate of antihypertensive drugs taking and rate of reaching the target blood pressure in cardiologists with different hospital level

\begin{tabular}{|c|c|c|c|c|c|c|}
\hline Variable & $\begin{array}{l}\text { Total } \\
(n=28924)\end{array}$ & $\begin{array}{l}\text { Primary } \\
(n=381)\end{array}$ & $\begin{array}{l}\text { Secondary } \\
(n=10823)\end{array}$ & $\begin{array}{l}\text { Tertiary } \\
(n=17375)\end{array}$ & $\begin{array}{l}\text { Others } \\
(n=345)\end{array}$ & $\begin{array}{l}P \\
\text { value }\end{array}$ \\
\hline Hypertension & $7319(25.30)$ & $136(35.70)$ & $2695(24.90)$ & $4413(25.40)$ & $75(21.74)$ & $<0.001$ \\
\hline Reaching the target blood pressure & 960 (41.33) & $8(21.05)$ & $390(43.14)$ & 551 (40.69) & $11(40.74)$ & 0.048 \\
\hline
\end{tabular}

Data are expressed as $\mathrm{n}(\%)$. 
be collected using a self-filled survey, which could introduce bias compared with a formal epidemiological study. In addition, the survey was filled only by the cardiologists willing to do so. Some physicians could be tempted to provide data that are better than the reality. Nevertheless, the prevalence of hypertension (based on the composite variable made of blood pressure and antihypertensive drugs, not on a formal inquiry about a diagnosis of hypertension) was similar to that of the general population of China, suggesting data validity. Of course, the medical system in China and the formation required to work in cardiology are different from that of other countries, ${ }^{6} 38$ limiting the generalisability of the data. The geographical distribution of the cardiologists across China was not taken into account. Importantly, the survey was not an epidemiological questionnaire and it was only used for data collection, not for assessment; validity and reliability were not verified. Finally, the characteristics of the cardiologists who were unwilling to fill the survey were not collected. Additional studies are necessary to confirm those findings.

In conclusion, the results suggest that Chinese cardiologists do not recognise and pay attention to their own blood pressure. Their rate of antihypertensive treatment was low. The identified risk factors could be used to identify cardiologists at higher risk for hypertension and for implementing preventive interventions. Our results have a number of implications for the reform of healthcare awareness and prevention in cardiologists in China.

Acknowledgements The authors acknowledge the contribution of all physicians who participated in this survey. The study was started by the Chinese Cardiovascular Association and supported by the GUSU group.

Contributors LH, XJ conceived and coordinated the study, designed, performed and analysed the experiments, wrote the paper. JM, JQ, YH carried out the data collection, data analysis and revised the paper. JG designed the study, carried out the data analysis and revised the paper. All authors reviewed the results and approved the final version of the manuscript.

Funding The study is supported by the Emerging Frontier Project of Shanghai Hospital Development Center (No. SHDC12014101), the Innovative Research Group Project of National Natural Science Foundation of China (No. 81521001), and National Key Research and Development Project (No. 2016YFC1301200).

Competing interests None declared.

Patient consent for publication Not required.

Ethics approval This study was approved by the Ethics Committee of Tongren Hospital, Shanghai Jiaotong University, School of Medicine (approval number: 2015017-01). All physicians signed the informed consent form before completing the questionnaire.

Provenance and peer review Not commissioned; externally peer reviewed. Data availability statement № data are available.

Open access This is an open access article distributed in accordance with the Creative Commons Attribution Non Commercial (CC BY-NC 4.0) license, which permits others to distribute, remix, adapt, build upon this work non-commercially, and license their derivative works on different terms, provided the original work is properly cited, appropriate credit is given, any changes made indicated, and the use is non-commercial. See: http://creativecommons.org/licenses/by-nc/4.0/.

\section{REFERENCES}

1. Goldstein JA, Balter S, Cowley M, et al. Occupational hazards of interventional cardiologists: prevalence of orthopedic health problems in contemporary practice. Catheter Cardiovasc Interv 2004;63:407-11.

2. Dehmer GJ. Occupational hazards for interventional cardiologists. Catheter Cardiovasc Interv 2006;68:974-6.

3. Clark DA. How much is too much? Catheter Cardiovasc Interv 2000;51:265

4. Faggianoi P, Temporelli PL, Zito G, et al. [Cardiovascular risk profile and lifestyle habits in a cohort of Italian cardiologists. Results of the SOCRATES survey]. Monaldi Arch Chest Dis 2013;80:118-25.

5. Michel JB, Sangha DM, Erwin JP. Burnout among cardiologists. Am J Cardiol 2017;119:938-40.

6. Gong Y, Huo Y. A survey of national cardiology workforce in China. Eur Heart J Suppl 2016;18(suppl A):A1-5.

7. Narang A, Sinha SS, Rajagopalan B, et al. The supply and demand of the cardiovascular workforce: striking the right balance. J Am Coll Cardiol 2016;68:1680-9.

8. Temporelli PL, Zito G, Faggiano P, et al. Cardiovascular risk profile and lifestyle habits in a cohort of Italian cardiologists (from the SOCRATES survey). Am J Cardiol 2013;112:226-30.

9. Merz CNB, Mensah GA, Fuster V, et al. Task Force \#5-the role of cardiovascular specialists as leaders in prevention: from training to champion. J Am Coll Cardiol 2002;40:641-9.

10. O'Kelly S, Andersen K, Capewell S, et al. Bringing prevention to the population: an important role for cardiologists in policy-making. Eur Heart J 2011;32:1964-7.

11. Aboyans V, Pinet $P$, Lacroix $P$, et al. Knowledge and management of smoking-cessation strategies among cardiologists in France: a nationwide survey. Arch Cardiovasc Dis 2009;102:193-9.

12. Reiner Željko, Sonicki Z, Tedeschi-Reiner E. Physicians' perception, knowledge and awareness of cardiovascular risk factors and adherence to prevention guidelines: The PERCRO-DOC survey. Atherosclerosis 2010;213:598-603.

13. Lu Y, Hu X-M, Huang X-L, et al. The relationship between job satisfaction, work stress, work-family conflict, and turnover intention among physicians in Guangdong, China: a cross-sectional study. BMJ Open 2017;7:e014894.

14. Liang $Y$, Wang $H$, Tao X. Quality of life of young clinical doctors in public hospitals in China's developed cities as measured by the Nottingham Health Profile (NHP). Int J Equity Health 2015;14:85.

15. Steering Committee of the Physicians' Health Study Research Group. Final report on the aspirin component of the ongoing physicians' health study. N Engl J Med 1989;321:129-35.

16. DY H, JM Y, Chen F, et al. The Chinese physicians' cardiovascular risk evaluation (care) survey: an assessment of physicians' own cardiovascular risks. Heart Asia 2010;2:89-94.

17. He J, Gu D, Chen J, et al. Premature deaths attributable to blood pressure in China: a prospective cohort study. The Lancet 2009;374:1765-72.

18. Miura K, Daviglus ML, Dyer AR, et al. Relationship of blood pressure to 25-year mortality due to coronary heart disease, cardiovascular diseases, and all causes in young adult men: the Chicago heart association detection project in industry. Arch Intern Med 2001;161:1501-8.

19. Franco $\mathrm{OH}$, Peeters $\mathrm{A}$, Bonneux L, et al. Blood pressure in adulthood and life expectancy with cardiovascular disease in men and women: life course analysis. Hypertension 2005;46:280-6.

20. Whelton PK, Carey RM, Aronow WS, et al. 2017 ACC/AHA/AAPA/ ABC/ACPM/AGS/APhA/ASH/ASPC/NMA/PCNA guideline for the prevention, detection, evaluation, and management of high blood pressure in adults: a report of the American College of Cardiology/ American heart association Task force on clinical practice guidelines. J Am Coll Cardiol 2018;71:e127-248.

21. Spruill TM. Chronic psychosocial stress and hypertension. Curr Hypertens Rep 2010;12:10-16.

22. Vrijkotte TGM, van Doornen LJP, de Geus EJC. Effects of work stress on ambulatory blood pressure, heart rate, and heart rate variability. Hypertension 2000;35:880-6.

23. Trudel X, Brisson C, Milot A, et al. Adverse psychosocial work factors, blood pressure and hypertension incidence: repeated exposure in a 5-year prospective cohort study. J Epidemiol Community Health 2016;70:402-8.

24. Calhoun DA, Harding SM. Sleep and hypertension. Chest 2010;138:434-43.

25. Wang $\mathrm{Y}$, Mei $\mathrm{H}$, Jiang $\mathrm{YR}$, et al. Relationship between duration of sleep and hypertension in adults: a meta-analysis. JCSM 2015;11:1047-56. 
26. Wu J, Cheng X, Qiu L, et al. Prevalence and clustering of major cardiovascular risk factors in China: a recent cross-sectional survey. Medicine 2016;95:e2712.

27. Lu Y, Wang $P$, Zhou T, et al. Comparison of prevalence, awareness, treatment, and control of cardiovascular risk factors in China and the United States. J Am Heart Assoc 2018;7.

28. Yang $\mathrm{F}$, Qian D, DY H, et al. Prevalence of cardiovascular disease risk factor clustering in Chinese adults. Clin Trials Regul Sci Cardiol 2016.

29. Sui H, Chen WW, Wang W. Interpretation of report on cardiovascular diseases in China 2015. Chin J Cardiovasc Med 2016;21:259-61.

30. Huang X-bo, Chen F, Dai W, et al. Prevalence and risk factors associated with hypertension in the Chinese Qiang population. Clin Exp Hypertens 2018;40:427-33.

31. Hu Y, Wang Z, Wang Y, et al. Prevalence, awareness, treatment, and control of hypertension among Kazakhs with high salt intake in Xinjiang, China: a community-based cross-sectional study. Sci Rep 2017;7:45547.

32. Abuissa $\mathrm{H}$, Lavie $\mathrm{C}$, Spertus $\mathrm{J}$, et al. Personal health habits of American cardiologists. Am J Cardiol 2006;97:1093-6.

33. Lloyd-Jones DM, Evans JC, Levy D. Hypertension in adults across the age spectrum: current outcomes and control in the community. Jama 2005;294:466-72.

34. James PA, Oparil S, Carter BL, et al. 2014 evidence-based guideline for the management of high blood pressure in adults: report from the panel members appointed to the eighth joint National Committee (JNC 8). Jama 2014;311:507-20.

35. Leung AA, Daskalopoulou SS, Dasgupta K, et al. Hypertension Canada's 2017 guidelines for diagnosis, risk assessment, prevention, and treatment of hypertension in adults. Can J Cardiol 2017;33:557-76.
36. Stockwell DH, Madhavan S, Cohen $\mathrm{H}$, et al. The determinants of hypertension awareness, treatment, and control in an insured population. Am J Public Health 1994;84:1768-74.

37. Berhe DF, Taxis K, Haaijer-Ruskamp FM, et al. Hypertension treatment practices and its determinants among ambulatory patients: retrospective cohort study in Ethiopia. BMJ Open 2017;7:e015743.

38. Levinson W, King TE, Goldman L, et al. Clinical decisions. American Board of internal medicine maintenance of certification program. $N$ Engl J Med 2010;362:948-52.

39. Song $\mathrm{P}$, Jin $\mathrm{C}$, Tang W. New medical education reform in China: towards healthy China 2030. Biosci Trends 2017;11:366-9.

40. The Lancet. Medical education reform in China. The Lancet 2017;390.

41. Chen X, Tan X, Li L. Health problem and occupational stress among Chinese doctors. Chin Med 2013;04:1-6.

42. Staiger DO, Auerbach DI, Buerhaus PI. Trends in the work hours of physicians in the United States. JAMA 2010;303:747-53.10.1001/ jama.2010.168

43. Conway SH, Pompeii LA, Roberts RE, et al. Dose-Response relation between work hours and cardiovascular disease risk: findings from the panel study of income dynamics. J Occup Environ Med 2016;58:221-6.

44. Wu Y, Huxley R, Li L, et al. Prevalence, awareness, treatment, and control of hypertension in China: data from the China national nutrition and health survey 2002. Circulation 2008;118:2679-86.

45. Wang J, Zhang L, Wang F, et al. Prevalence, awareness, treatment, and control of hypertension in China: results from a national survey. Am J Hypertens 2014;27:1355-61. 